\title{
Article \\ Intrinsic Blue Fluorescence of 2.0G PAMAM-DCM Polymer Dots and Its Applications for $\mathrm{Fe}^{3+}$ Sensing
}

\author{
Xin Wang ${ }^{1} \mathbb{D}$, Weiguang Shi ${ }^{1,2, * \mathbb{D}}$, Yuda Wang ${ }^{3}$, Dan Cheng ${ }^{4}$, Jiahui Liu ${ }^{1}$, Shihan Xu ${ }^{5}$, Wei Liu ${ }^{6}$, Biao Dong ${ }^{6}$ \\ and Jiao $\operatorname{Sun}^{3, *}$
}

check for updates

Citation: Wang, X.; Shi, W.; Wang, Y.; Cheng, D.; Liu, J.; Xu, S.; Liu, W.; Dong, B.; Sun, J. Intrinsic Blue Fluorescence of 2.0G PAMAM-DCM Polymer Dots and Its Applications for $\mathrm{Fe}^{3+}$ Sensing. Sensors 2022, 22, 1075. https://doi.org/10.3390/ s22031075

Academic Editor: Roberto Pizzoferrato

Received: 24 December 2021 Accepted: 27 January 2022 Published: 29 January 2022

Publisher's Note: MDPI stays neutral with regard to jurisdictional claims in published maps and institutional affiliations.

Copyright: (C) 2022 by the authors. Licensee MDPI, Basel, Switzerland. This article is an open access article distributed under the terms and conditions of the Creative Commons Attribution (CC BY) license (https:// creativecommons.org/licenses/by/ $4.0 /)$.
1 College of Chemistry \& Chemical Engineering, Northeast Petroleum University, Daqing 163318, China; wx18756130799@163.com (X.W.); L19845920393@163.com (J.L.)

2 Key Laboratory of Continental Shale Hydrocarbon Accumulation and Efficient Development, Ministry of Education, Northeast Petroleum University, Daqing 163318, China

3 Department of Cell Biology, College of Basic Medical Sciences, Jilin University, Changchun 130021, China; wangyuda2022@163.com

4 Daqing Ecological Environment Monitoring Center, Daqing 163318, China; chengdan83@163.com

5 Department of Bioengineering, University of Washington, Seattle, WA 98195, USA; xushihan@uw.edu

6 State Key Laboratory on Integrated Optoelectronics, College of Electronic Science and Engineering, Jilin University, Changchun 130012, China; liu_wei21@mails.jlu.edu.cn (W.L.); dongb@jlu.edu.cn (B.D.)

* Correspondence: sswwgg2004@gmail.com (W.S.); Jiaosun@jlu.edu.cn (J.S.)

\begin{abstract}
A typical and environment-friendly fluorescent polyamine-amine (PAMAM) features good compatibility and unique surface modification, while it is restricted by a low fluorescence property performance and an unclear fluorescence mechanism. In this work, we prepared blue fluorescent PAMAM polymer dots (PDs) via a simple hydrothermal method based on dichloromethane (DCM) and 2.0G PAMAM. The quantum yield achieved was $32.1 \%$, which was 25 times stronger than that of 2.0G PAMAM due to the lone-pair electron leap of the amine groups, the aggregation of carbonyl groups, as well as the crosslinking induced by DCM inside the PAMAM. In addition, the fluorescent 2.0G PAMAM-DCM PDs show a great $\mathrm{Fe}^{3+}$ sensing property with the detection limit of $56.6 \mathrm{nM}$, which is much lower than the safety limits $(5.36 \mu \mathrm{M})$ in drinking water, indicating its great potential for $\mathrm{Fe}^{3+}$ detection in aqueous media.
\end{abstract}

Keywords: PAMAM; polymer dots; fluorescent mechanism; metal ionic sensing

\section{Introduction}

Polyamide-amine (PAMAM) is a highly symmetrical macromolecule with an internal cavity: exhibits good compatibility, unique hydrodynamic properties, and easy modification properties [1-3]; receives increasing attention in bioimaging [4,5], sensors [6], catalysis [7,8], drug-delivery [9,10], etc. Previously, Wang and Imae [11] reported that PAMAM, with different terminal groups, including $-\mathrm{NH}_{2},-\mathrm{C}=\mathrm{O}$, or $-\mathrm{OH}$, could present weak and blue fluorescence. PAMAM-based fluorescent carbon/polymer materials can be prepared by the surface modification method to obtain efficient fluorescence, suggesting that the fluorescence properties are related to the generations of PAMAM and pH [12-14]. These studies are helpful to gain a better understanding of the relationship between the internal backbone and fluorescence. Recent studies have concluded that the fluorescence properties of PAMAM will be affected by special conditions, including the oxidation of tertiary amines, photoelectron transfer, and the aggregation of internal carbonyl groups [15-17]. This indicates that at least two fluorescence sites are inside the PAMAM, influenced by $\mathrm{pH}$ or temperature [18-21]. Therefore, the stability of PAMAM and its fluorescent property will be limited.

The development of polymer carbon dots (PCDs, PDs) solved the unstable fluorescence problem of polymers $[22,23]$. Note that polymer carbon dots are zero-dimensional and mildly 
carbonized nanomaterials with unique core-shell structures composing internal carbon and external polymer, which can greatly enhance the fluorescence property and stability [24,25]. With external shell modification, carbon dots can be further multi-functionalized.

Meanwhile, PCDs, as a fluorescence sensor, [26,27] show great applications in environmental sciences [28,29], chemical analysis [30], and biological fields [31-33]. In contrast to the instrumental detection of metal ions, PD fluorescence sensors are simple, portable, highly efficient, and fast-responding [34]. Most organics-based fluorescent probes are hydrophobic and toxic, resulting in poor water solubility and low detection sensitivity [35]. PAMAM-based PDs could be a good candidate as a fluorescent sensor with improved detection performance for metal ions, owing to their good compatibility, nontoxicity, and easy surface modification. However, for better sensing performance, the fluorescence efficiency of PAMAM should be improved. Moreover, the utilization of PDs is still hindered by unclear fluorescent mechanisms due to their complicated structures, which is also an urgent problem that needs to be solved.

In this paper, dichloromethane (DCM) was employed as raw material to react with the amino group of PAMAM via a nucleophilic substitution reaction. Diaz et al. reported that DCM is easier to react with a tertiary amine, followed by a secondary amine, which is difficult to react with a primary amine [1]. Thus, DCM is a suitable candidate for investigating the internal fluorescence mechanism of PAMAM. In order to enhance the fluorescence intensity of PAMAM-based PDs, 2.0G PAMAM and DCM were combined to obtain 2.0G PAMAM-DCM PDs by the one-pot hydrothermal method. It exhibits remarkable water solubility, strong blue fluorescence, and $\mathrm{pH}$ - and temperature-responsive properties. The intrinsic fluorescence mechanism of 2.0G PAMAM-DCM PDs was investigated by focusing on the amine group and carbonyl group. DCM can restrict the transfer, rotation, and vibration of lone-pair of electrons on the amine group, promoting the crosslinking and aggregation of functional groups in PAMAM and presenting efficient fluorescent properties (quantum yield of 32.1\%). Moreover, the fluorescent properties of 2.0G PAMAM-DCM PDs were studied under different conditions, such as $\mathrm{pH}$, temperature, and concentrations. In addition, the enhanced sensing of $\mathrm{Fe}^{3+}$ ions was achieved with a detection limit of $56.6 \mathrm{nM}$, which indicates its potential applications in environmental monitoring.

\section{Materials and Methods}

\subsection{Reagents}

Methyl acrylate (98\%), ethylenediamine (99\%), methanol (98\%), dichloromethane (99\%), hydrochloric acid (AR, $35 \mathrm{wt} \%)$, sodium hydroxide (98\%), $\mathrm{H}_{3} \mathrm{PO}_{4}(\mathrm{AR}), \mathrm{KCl}(\mathrm{AR})$, $\mathrm{HgCl}_{2}(\mathrm{AR}), \mathrm{CaCl}_{2}(\mathrm{AR}), \mathrm{NaCl}(\mathrm{AR}), \mathrm{CuCl}_{2}(\mathrm{AR}), \mathrm{MgCl}_{2}$ (AR), $\mathrm{CdCl}_{2}$ (AR), $\mathrm{HgCl}_{2}$ (AR), $\mathrm{ZnCl}_{2}(\mathrm{AR}), \mathrm{FeCl}_{3}$, and $\mathrm{AlCl}_{3}$ (AR) were purchased from Aladdin Reagent Co., Ltd. (Shanghai, China). Disodium hydrogen phosphate (98\%), sodium dihydrogen phosphate (98\%), and quinine sulfate (98\%) was purchased from Macklin Biochemical Co., Ltd. (Shanghai, China). Deionized water was made in our laboratory.

\subsection{Experimental Methods}

\subsubsection{Synthesis of 0.5G PAMAM, 1.0G PAMAM and 2.0G PAMAM}

Different generations of PAMAM were synthesized by a divergent method. The synthesis sequence of PAMAM products is $0.5 \mathrm{G}$ PAMAM $\rightarrow$ 1.0G PAMAM $\rightarrow 2$.0G PAMAM. Firstly, a Michael addition reaction was performed. Ethylenediamine was dissolved with $1.2 \mathrm{~g}$ into $50 \mathrm{~mL}$ methanol solution. Then, they were transferred to a cold-water bath in a three-necked flask for $30 \mathrm{~min}$. Methyl acrylate $(13.5 \mathrm{~g})$ was added dropwise through a constant pressure funnel and stirred at $30{ }^{\circ} \mathrm{C}$ for $36 \mathrm{~h}$. The excess methyl acrylate and methanol were evaporated by the reduced pressure distillation method at $55^{\circ} \mathrm{C}$, and $7.8 \mathrm{~g}$ 0.5G PAMAM products were obtained. Secondly, $4.04 \mathrm{~g}$ of 0.5G PAMAM was dissolved in $60 \mathrm{~mL}$ methanol solution; $5.16 \mathrm{~g}$ of ethylenediamine was added dropwise to the above solution and stirred for $30 \mathrm{~min}$. The reaction was carried out at $30^{\circ} \mathrm{C}$ for $24 \mathrm{~h}$. The solution 
was evaporated by rotation at $75{ }^{\circ} \mathrm{C}$, and $5.0 \mathrm{~g}$ of $1.0 \mathrm{G}$ PAMAM was obtained. Finally, $2.0 \mathrm{G}$ PAMAM was synthesized through the repeated steps above.

\subsubsection{Synthesis of 2.0G PAMAM-DCM PDs}

The 2.0G PAMAM-DCM PDs were obtained via a hydrothermal method. 2.0G PAMAM$\mathrm{NH}_{2}(0.2 \mathrm{mM})$ were dissolved for use. Then, PAMAM (aq) and $5.0 \mathrm{~mL}$ dichloromethane were added into a stainless-steel autoclave $(25 \mathrm{~mL})$ for oil bath; the $\mathrm{pH}$ of the solutions was adjusted using $\mathrm{HCl}$ solution $(0.1 \mathrm{M})$ or $\mathrm{NaOH}(0.1 \mathrm{M})$. The resulting solution was then treated by a one-step hydrothermal method under different conditions, including temperature $\left(60-140^{\circ} \mathrm{C}\right), \mathrm{pH}(3-11)$ and concentrations $(0.01-0.1 \mathrm{mM})$. The pure PDs were obtained by centrifugation and vacuum rotary evaporation, and freeze-dried.

\subsection{Measurements}

The fluorescence spectra of the resultant polymers were recorded at room temperature on a fluorescence spectrophotometer (LS-55, Perkin-Elmer, Wellesley, MA, USA). The slits of excitation and emission were $10.0 \mathrm{~nm}$ and $2.5 \mathrm{~nm}$, respectively, with a scanning rate of $200 \mathrm{~nm} \cdot \mathrm{min}^{-1}$. All measurements were performed at room temperature. The morphology and the structure of the sample were analyzed by a high-resolution transmission electron microscope (HR-TEM) (Tecnai G ${ }^{2}$ F20 S-Twin, FEI, Hillsboro, FL, USA) at an accelerating voltage of $200 \mathrm{kV}$. UV-Vis absorption spectra were recorded using a UV spectrophotometer (UV-Vis) (UV-1700 PharmaSpec, Kemeijia, China). Ultra-pure water was used as the reference solution, and the wavelength range was $200-600 \mathrm{~nm} .{ }^{1} \mathrm{H}$ NMR spectra were collected on a 400-MHz Bruker NMR spectrometer (AV400, Bruker, Ettlingen, Germany), with the freeze-dried product dissolved in $\mathrm{D}_{2} \mathrm{O}$. Fourier transform infrared spectra (FT-IR) were performed on a Bruker FT-IR spectrometer (Tensor27, Bruker, Leipzig, Germany), and the scanning time was set to 5 times per minute. The $\mathrm{pH}$ values of the solutions were measured with a $\mathrm{pH}$ meter (PHS-3E, Shanghai Leici Instrument Company, Shanghai, China).

Quinine sulfate $\left(0.1 \mathrm{M} \mathrm{H}_{2} \mathrm{SO}_{4}\right.$ as the solvent, $\left.\mathrm{QY}=54 \%\right)$ was chosen as the standard. The QY of PDs (in water) was calculated by the reference point method:

$$
\phi_{\mathrm{x}}=\left(\mathrm{A}_{\mathrm{n}} / \mathrm{A}_{\mathrm{x}}\right)\left(\int F_{\mathrm{x}} / \int F_{\mathrm{n}}\right) \phi_{\mathrm{n}}
$$

where $\phi$ is the QY, $\mathrm{A}$ is the absorbance $(0.01<\mathrm{A}<0.05$, to minimize self-absorption effects), and $\int F$ is the integrated area of the emission spectrum $\left(\lambda_{\mathrm{EX}}=360 \mathrm{~nm}\right)$. The subscript " $\mathrm{n}$ " refers to the standard with known QY and " $\mathrm{x}$ " for the sample (PDs).

\section{Results and Discussion}

\subsection{0G PAMAM-DCM PDs}

The 2.0G PAMAM-DCM PDs were prepared by the hydrothermal method at $100^{\circ} \mathrm{C}$. As shown in Figure 1A, the 2.0G PAMAM-DCM solution exhibits a stronger blue fluorescence under the UV light $(\lambda \mathrm{ex}=365 \mathrm{~nm})$, and the HR-TEM image shows a mild carbonization nano dot $(2.12 \mathrm{~nm})$ with no obvious crystal lattice, indicating that 2.0G PAMAM-DCM PDs are a kind of PDs, but not pure CDs. To further prove that the PDs retain the properties of the polymer, FTIR spectra and ${ }^{1} \mathrm{H}$ NMR were analyzed for their molecular structures and functional groups. The absorption peak at $3284 \mathrm{~cm}^{-1}$ and $3080 \mathrm{~cm}^{-1}$ were attributed to the stretching vibration of $-\mathrm{NH}_{2}$, presenting in both 2.0G PAMAM-DCM PDs and 2.0G PAMAM. It indicated that the peripheral primary amines in PAMAM did not react with DCM. The stretching vibration of $\mathrm{C}=\mathrm{O}\left(1643 \mathrm{~cm}^{-1}\right)$ and $\mathrm{C}-\mathrm{N}\left(1385 \mathrm{~cm}^{-1}\right)$ co-existed in the two systems, suggesting that the structural characteristics of the polymer are preserved. Meanwhile, the peak near $2100 \mathrm{~cm}^{-1}$ was a newborn vibration from the reaction between tertiary amine and DCM [36]. The secondary amine could also bind with the DCM to form $\mathrm{C}-\mathrm{N}$ (Figure 1B). Consequently, DCM promoted the crosslinking of intramolecular amine groups, the aggregation of carbonyl groups, and the formation of large bond conjugation, which reduced the electron cloud density in the systems [37]. Figure $1 \mathrm{C}$ documents a 
unified low-frequency shift of the peaks in the range of 2-4 ppm, and two new-born chemical shifts of 4.2 and $5.2 \mathrm{ppm}$, which resulted from the decreased electron density by polymer crosslinking, induced by the reaction between the tertiary amine or secondary amine in PAMAM and DCM. These observations suggest that 2.0G PAMAM-DCM are PDs with special features of the combination of carbon dots and polymers.
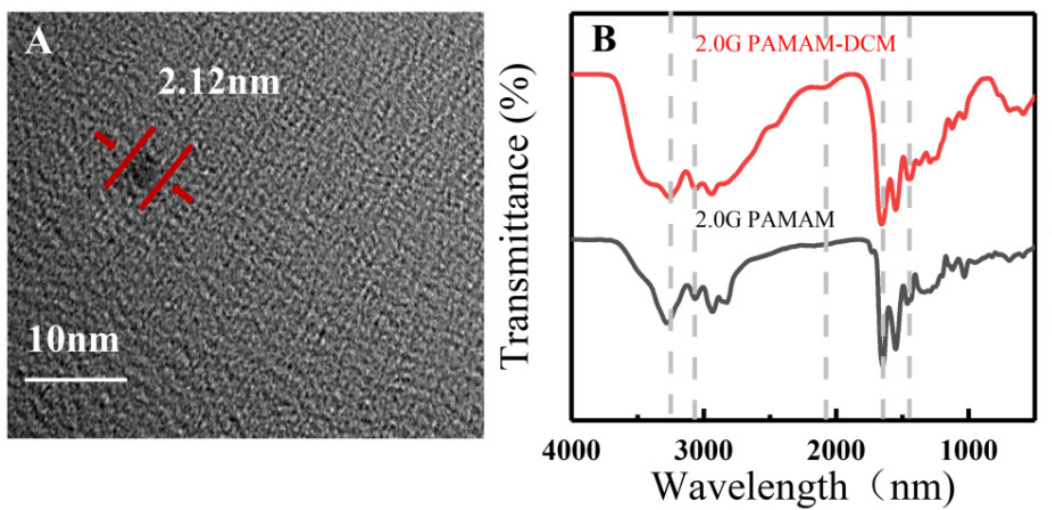

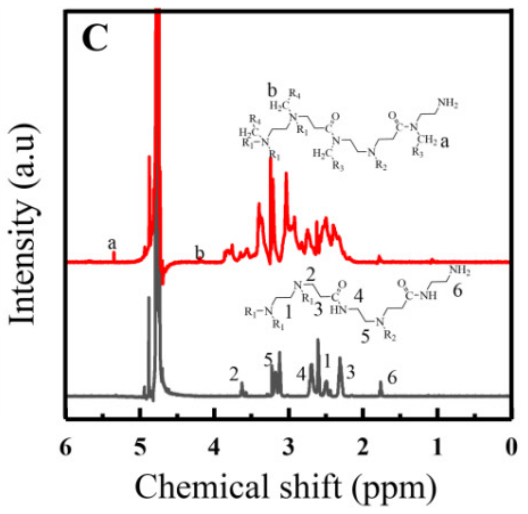

Chemical shift (ppm)

Figure 1. (A) TEM image of 2.0G PAMAM-DCM PDs. (B) FT-IR spectra and (C) ${ }^{1} \mathrm{H}$ NMR of $2.0 \mathrm{G}$ PAMAM and 2.0G PAMAM-DCM.

To further investigate the fluorescence properties and the fluorescence mechanism of 2.0G PAMAM-DCM PDs, experiments were carried out in different conditions, such as concentration, temperature, and $\mathrm{pH}$.

\subsection{Fluorescence Properties of 2.0G PAMAM-DCM PDs}

The UV-Vis absorption spectra and the fluorescence spectra of 2.0G PAMAM and 2.0G PAMAM-DCM PDs are shown in Figure 2. It can be seen that two absorption bands in the 2.0G PAMAM-DCM PDs are consistent with: $\pi \rightarrow \pi^{*}$ electronic transition (225 nm), as large as the $\pi$-conjugated off-domain system. It was formed by a combination of the crosslinking of intramolecular amine groups and the aggregation of carbonyl groups: the $\mathrm{n} \rightarrow \pi^{*}$ electronic transition ( $303 \mathrm{~nm}$ ) corresponding to $\mathrm{C}=\mathrm{O}$. Additionally, there is only one absorption band which is assigned to the $n \rightarrow \pi^{*}$ electronic transition of $\mathrm{C}=\mathrm{O}$ in 2.0G PAMAM (Figure 2A). Meanwhile, the emission peak was significantly red-shifted by varying the excitation wavelengths from 240 to $410 \mathrm{~nm}$ (Figure 2B). When excited at $390 \mathrm{~nm}$, it emitted blue light, with the emission peak located at $450 \mathrm{~nm}$. When the emission wavelength was fixed at $450 \mathrm{~nm}$, the excitation spectra showed large different intensities at two peaks, located at $260 \mathrm{~nm}$ and $390 \mathrm{~nm}$ (Figure 2C). When excited at $390 \mathrm{~nm}$, weak fluorescence intensity was observed from 2.0G PAMAM, while the 2.0G PAMAM-DCM PDs solution appeared light-yellow in color and exhibited a strong blue fluorescence (Figure 2D). 

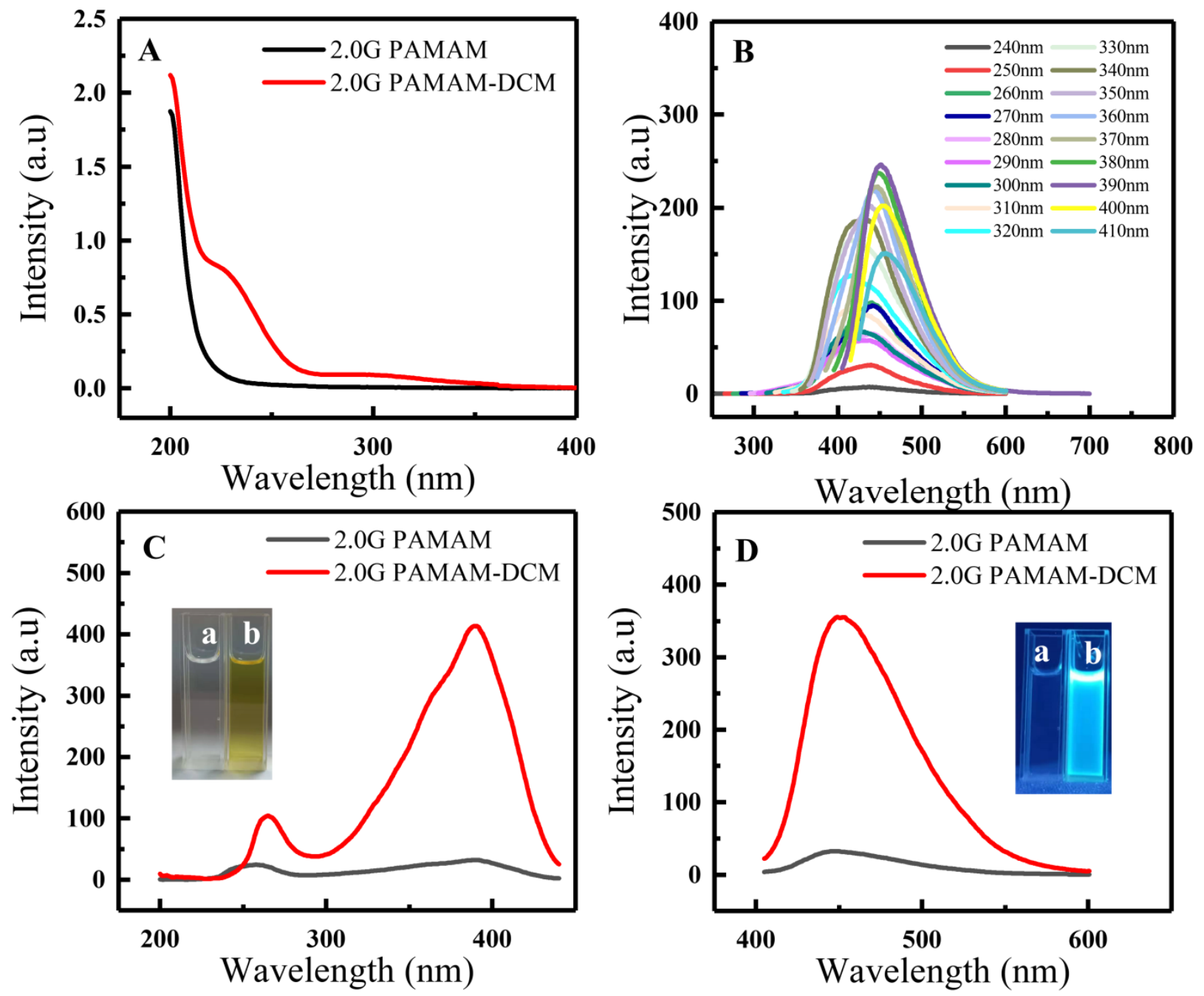

Figure 2. (A) UV-Vis spectra; (B) fluorescence emission spectra of 2.0G PAMAM-DCM PDs under different excitation wavelengths, $(C)$ excitation spectra $\left(\lambda_{\mathrm{EM}}=450 \mathrm{~nm}\right)$, and $(D)$ emission spectra of 2.0G PAMAM and the 2.0G PAMAM-DCM PDs $\left(\lambda_{\mathrm{EX}}=390 \mathrm{~nm}\right.$ ). (a) 2.0G PAMAM, (b) 2.0G PAMAM-DCM. In the insets of $(B, C)$ are photographs taken under sunlight and UV light $\left(\lambda_{E X}=365 \mathrm{~nm}\right)$, respectively.

\subsubsection{Effects of Concentrations on the Fluorescence Properties}

According to previous research, the concentration of the precursor an important parameter that can affect the numbers and dispersion degree of fluorescent groups during the formation of PDs, resulting in a great fluorescent diversity [38]. Five different concentrations, with the range from 0.01 to $0.1 \mathrm{~mol} / \mathrm{L}$ of $2.0 \mathrm{G}$ PAMAM, were employed for thermal reaction at $100{ }^{\circ} \mathrm{C}$ for $3 \mathrm{~h}$. In Figure $3 \mathrm{~A}, \mathrm{~B}$, a progressive enhancement trend of fluorescence intensity was recorded with the increasing concentrations of 2.0G PAMAM, from 0.01 to $0.1 \mathrm{~mol} / \mathrm{L}$, and the yellow and blue color of the PDs solutions gradually deepened under sunlight and UV light, respectively. These observations suggest that the degree of the crosslinking of intramolecular amine groups and the aggregation of carbonyl groups increases with increasing concentrations of 2.0G PAMAM. To further verify the effect of self-quenching on fluorescence of the PDs solutions, the concentration of 2.0G PAMAM precursor was fixed at $0.1 \mathrm{~mol} / \mathrm{L} ; 2.0 \mathrm{G}$ PAMAM-DCM PDs were distributed into the water, obtaining the concentrations from 0.1 to $5 \mathrm{mg} / \mathrm{mL}$. As shown in Figure 3C,D, the fluorescence intensity presented a curvilinear upward trend from 0.1 to $5 \mathrm{mg} / \mathrm{mL}$. When the concentration was greater than $4 \mathrm{mg} / \mathrm{mL}$, the fluorescence intensity decreased due to its self-quenching. These results are generally in agreement with the earlier research [39]. 

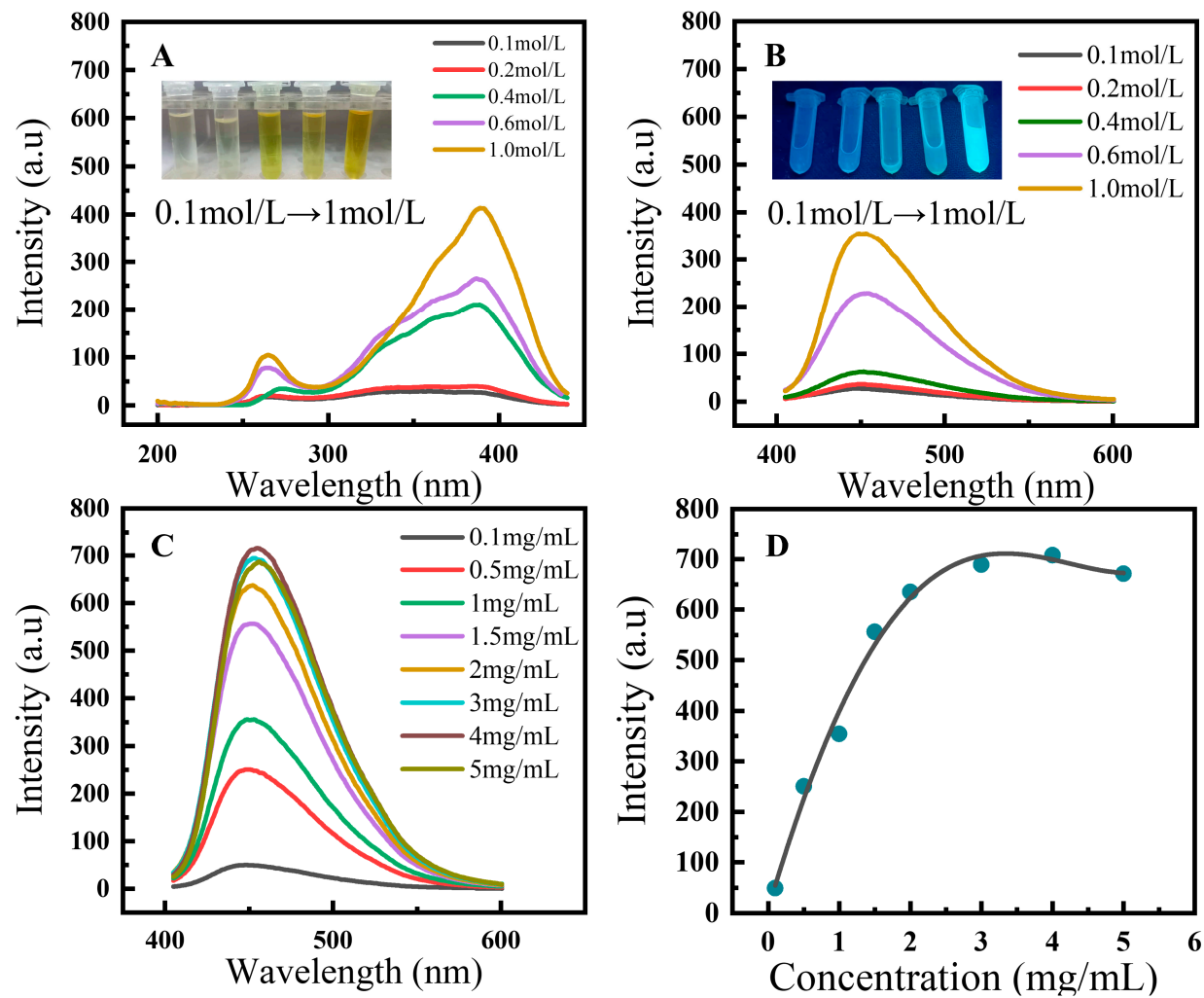

Figure 3. (A) Fluorescence excitation and (B) emission $\left(\lambda_{\mathrm{EX}}=390 \mathrm{~nm}\right)$ spectra at various concentrations of 2.0G PAMAM. (C) Emission $\left(\lambda_{\mathrm{EX}}=390 \mathrm{~nm}\right)$ spectra at various concentrations of 2.0G PAMAM-DCM PDs solutions. (D) Curve-fitting for the fluorescence intensity and 2.0G PAMAMDCM PDs concentration. $Y=479.96 X-87.82 X^{2}-0.939 X^{3}+0.92 X^{4}+7.38, R^{2}=0.991$; where $Y$ is fluorescence intensity, $X$ is the concentration. Inset in $(\mathbf{A}, \mathbf{B})$ are photographs of 2.0G PAMAMDCM PDs with different concentrations, from left to right, taken under sunlight and UV light $\left(\lambda_{\mathrm{EX}}=365 \mathrm{~nm}\right)$, respectively.

\subsubsection{Effects of Temperature on the Fluorescence Properties}

Previous reports conclude that temperature is considered an important parameter to control the carbonization degrees. To investigate the influence of different reaction temperatures on the fluorescence properties of 2.0G PAMAM-DCM PDs, experiments were carried out at $60{ }^{\circ} \mathrm{C}, 80^{\circ} \mathrm{C}, 100^{\circ} \mathrm{C}, 120^{\circ} \mathrm{C}$, and $140{ }^{\circ} \mathrm{C}$, respectively. In this work, $100{ }^{\circ} \mathrm{C}$ was the initial temperature to form 2.0G PAMAM-DCM PDs with the highest fluorescent intensity. The fluorescence intensities decreased at $120^{\circ} \mathrm{C}$ and $140{ }^{\circ} \mathrm{C}$. The solutions were scarcely colored under sunlight at $60^{\circ} \mathrm{C}$ and $80^{\circ} \mathrm{C}$, with no fluorescent intensities (Figure 4A,B).

However, 2.0G PAMAM-DCM PDs began to transform into CDs when the reaction temperature was higher than $100{ }^{\circ} \mathrm{C}$. When increasing the temperature from $120^{\circ} \mathrm{C}$ to $140{ }^{\circ} \mathrm{C}$, the average particle size of CDs regularly increased from $2.48 \mathrm{~nm}$ to $4.36 \mathrm{~nm}$. Moreover, well-resolved lattice fringes were observed clearly in the HRTEM image (Figure 4C,D). The interplanar spacing also increased, from $0.18 \mathrm{~nm}$ to $0.23 \mathrm{~nm}$, which is close to the (100) diffraction facets of graphite carbon. These processes of polymer carbonization are generally in agreement with earlier research $[22,23]$. The fluorescence intensities of $2.0 \mathrm{G}$ PAMAM-DCM PDs were different, but the emission positions did not change at $100{ }^{\circ} \mathrm{C}$ or $140{ }^{\circ} \mathrm{C}$, suggesting the temperature-responsive fluorescence property. The results indicate that $100^{\circ} \mathrm{C}$ is the optimal temperature for the stable molecular structure of 2.0G PAMAMDCM PDs, while $120-140{ }^{\circ} \mathrm{C}$ is the optimal temperature for the stable fluorescence property of 2.0G PAMAM-DCM CDs. 

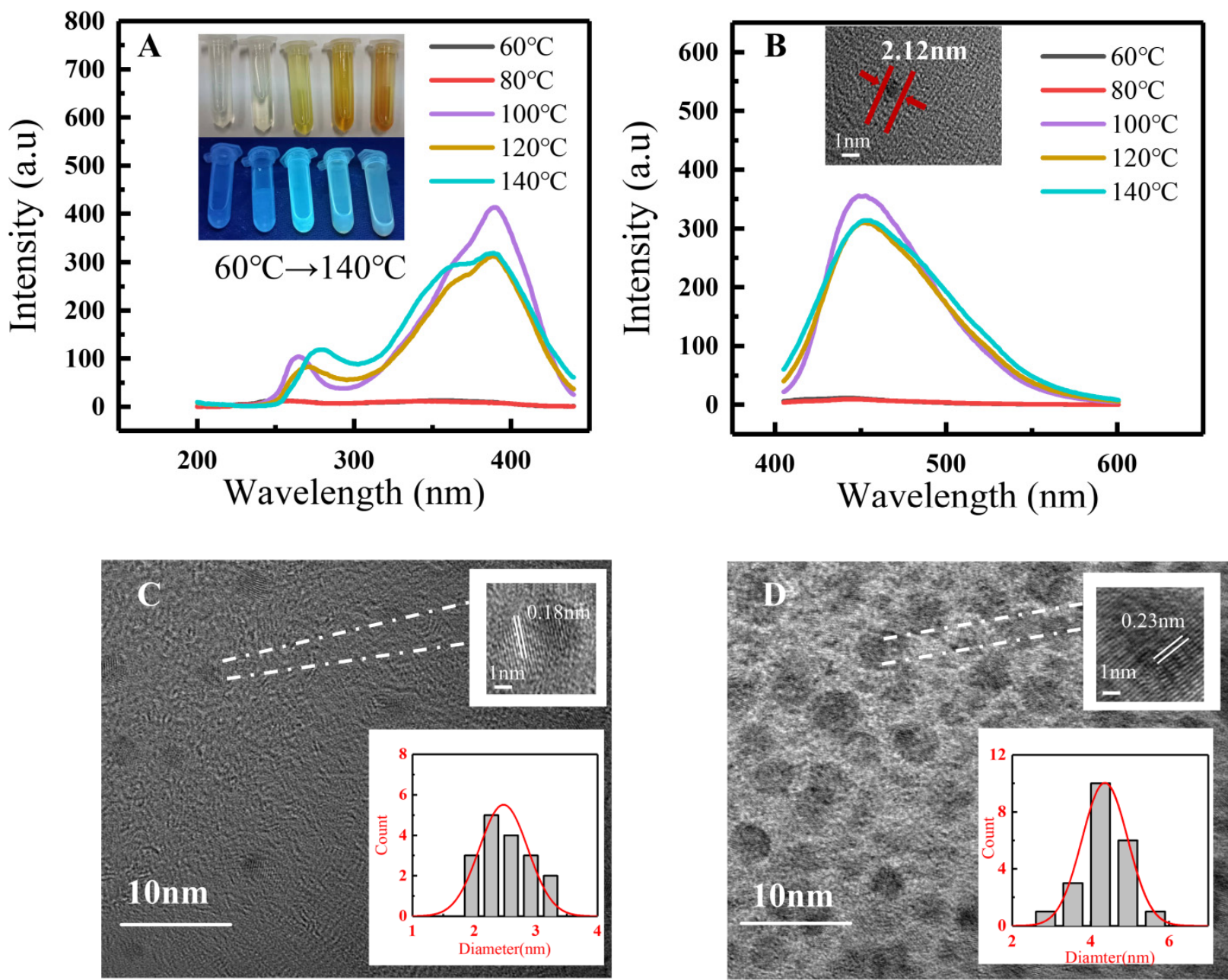

Figure 4. (A) Fluorescence excitation spectra and (B) emission spectra of the 2.0G PAMAM-DCM PDs $(\lambda E X=390 \mathrm{~nm}) .(\mathrm{C}, \mathrm{D})$ : TEM of 2.0G PAMAM-DCM PDs at $120^{\circ} \mathrm{C}$ and $140{ }^{\circ} \mathrm{C}$, respectively. Insets in (A) are photographs taken at different temperatures under sunlight and UV light $(\lambda \mathrm{EX}=365 \mathrm{~nm})$, respectively. Insets in (B-D) are HRTEM images of 2.0G PAMAM-DCM PDs at $100{ }^{\circ} \mathrm{C}, 120^{\circ} \mathrm{C}$, and $140^{\circ} \mathrm{C}$, respectively.

\subsubsection{Effects of $\mathrm{pH}$ on the Fluorescence Properties}

Inarguably, the crosslinking degree, the strength of the hydrogen bond, and the chemical reaction of functional groups of PAMAM molecules can be controlled by $\mathrm{pH}$ [11], by changing charge distributions, and by intrinsic emissions. Thus, $\mathrm{pH}$ is an emissionrelated factor that can affect fluorescence properties. In this case, the $\mathrm{pH}$ sensitivity of $2.0 \mathrm{G}$ PAMAM-DCM PDs was recorded, with the fluorescence spectrum at a fixed excitation wavelength of $390 \mathrm{~nm}$. Figure 5A,C document a first upward and then downward tendency of fluorescence intensity in the $\mathrm{pH}$ range from 3.02 to 10.75 . There are no fluorescence spectra shifts, and the maximum emission intensity is obtained at $\mathrm{pH}$ 7.24. Moreover, the emission intensity is high enough at pHs ranging from 3.02 to 10.75 and maintains stability and fluorescence intensity, which can extend to a wide range of applications, such as environmental monitoring. From the aspect of $\mathrm{pH}$ sensitivity, the amine groups are protonated in the condition of $\mathrm{pH}<7$; isomerization phenomena would happen to destroy the nucleophilicity of DCM [18]. In the condition of $\mathrm{pH}>7$, the fluorescence intensity becomes weak, owing to DCM restricting the electron movement of the amine group, as well as the rotation and vibration in PAMAM, weakening the crosslinking of the internal carbonyl group [40]. Meanwhile, compared with lower fluorescence intensities in the control system of 2.0G PAMAM (Figure 5B), this indicates that the reaction between DCM 
and amine groups can form large bond conjugations and crosslinking, which can enhance the fluorescence properties. In contrast to 1.0G PAMAM-DCM PDs, the results suggest that a similar variation tendency of fluorescence presents under the same $\mathrm{pH}$, but the fluorescence intensity (Figure 5D-F), indicates that 2.0 G PAMAM has multiple amine and carbonyl functional groups to form fluorescent sites. These observations indicate that DCM reacts with the amines that are inside the PAMAM, but not the external $-\mathrm{NH}_{2}$.
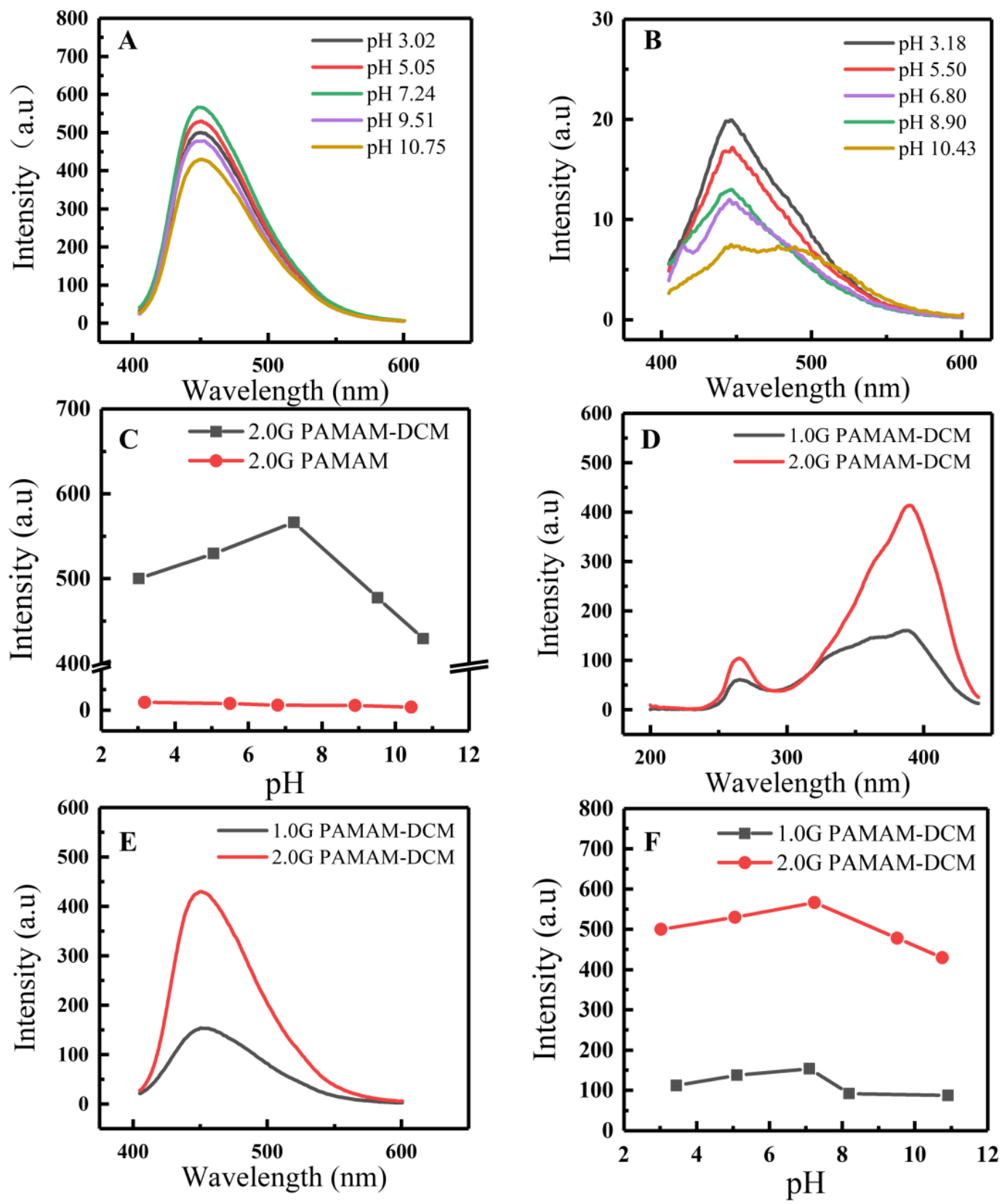

Figure 5. Fluorescence emission $\left(\lambda_{\mathrm{EX}}=390 \mathrm{~nm}\right.$ ) spectra of (A) 2.0G PAMAM-DCM PDs, (B) 2.0G PAMAM, and $(C)$ fluorescence intensity $\left(\lambda_{\mathrm{EM}}=450 \mathrm{~nm}\right)$ at various $\mathrm{pH}$; (D) fluorescence excitation and $(E)$ emission $\left(\lambda_{\mathrm{EX}}=390 \mathrm{~nm}\right)$ spectra of 1.0G PAMAM-DCM PDs and 2.0G PAMAM-DCM PDs, and $(\mathbf{F})$ fluorescence intensity $\left(\lambda_{\mathrm{EM}}=450 \mathrm{~nm}\right)$ at various $\mathrm{pH}$.

\subsection{Possible Fluorescence Mechanism of 2.0G PAMAM-DCM PDs}

To identify if an important fluorescence center in 2.0G PAMAM-DCM PDs is induced by $\mathrm{C}=\mathrm{O}$ bonds and their aggregations, a reaction (Scheme 1 ) was conducted by reducing 
the $\mathrm{C}=\mathrm{O}$ bond to an alcoholic hydroxyl group by sodium borohydride $\left(\mathrm{NaBH}_{4}\right)$ to explore the variation of fluorescence properties.<smiles>CC(=O)[C@H](C)C(C)O</smiles>

Scheme 1. The chemical formula for the reduction reaction of carbonyl.

An experiment was carried out by adding an excessive amount of $\mathrm{NaBH} 4$ in the 2.0G PAMAM-DCM PDs solution for $4 \mathrm{~h}$ at $40{ }^{\circ} \mathrm{C}$. The different results before and after reductions are summarized in Figure 6A,B. A great decreasing tendency of fluorescence intensity was recorded after reduction, and the color of the PDs solutions gradually became colorless and weakly blue under sunlight and UV light, respectively. This indicated that a massive amount of fluorescence centers, caused by $n \rightarrow \pi *$ transitions, had vanished, together with a part of large $\pi$-bond conjugation induced by DCM, which is proved by the UV spectrum. As a result, the UV adsorption bands at $225 \mathrm{~nm}$ and $303 \mathrm{~nm}$ disappeared, which was attributed to $\pi \rightarrow \pi^{*}$ electronic transition. The $n \rightarrow \pi^{*}$ electronic transition also indicated that the $\pi$-conjugated off-domain system was destroyed, $\mathrm{C}=\mathrm{O}$ was reduced, and the combination of the crosslinking of intramolecular amine groups and the aggregation of carbonyl groups was dissolved (Figure 6C). Only the crosslinking of intramolecular amine groups caused by DCM was residually viable at the 278-nm adsorption band, emitting the blue light.
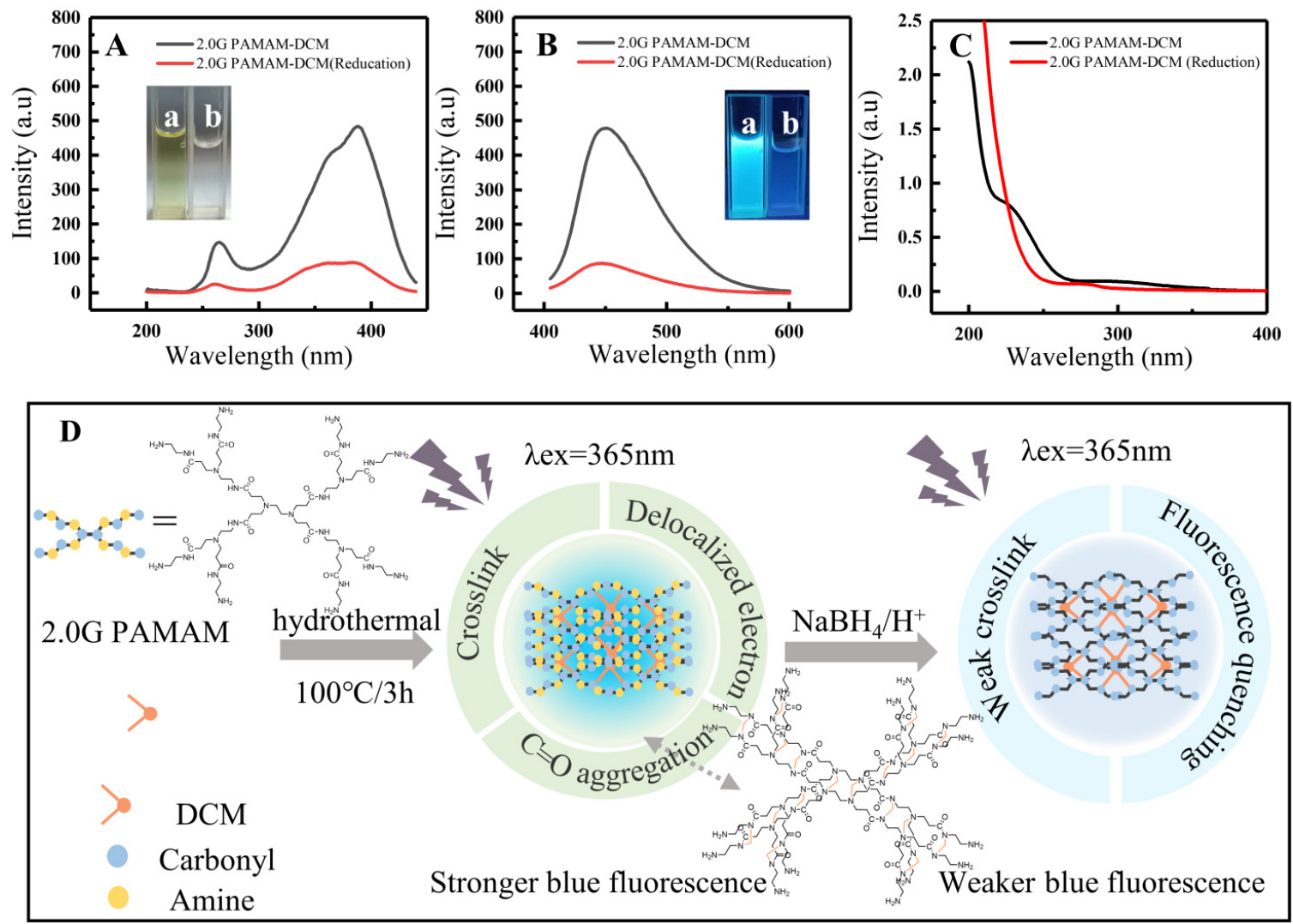

Figure 6. (A) Fluorescence excitation, (B) emission spectrum $\left(\lambda_{\mathrm{EX}}=390 \mathrm{~nm}\right)$, and (C) UV-Vis spectrum of 2.0G PAMAM-DCM PDs and 2.0G PAMAM-DCM PDs reduced by $\mathrm{NaBH}_{4}$. (D) The 
schematic diagram for the possible fluorescence mechanism of 2.0G PAMAM-DCM PDs. Insets in $(\mathbf{A}, \mathbf{B})$ are photographs of (a) 2.0G PAMAM-DCM PDs and the reduced (b) 2.0G PAMAM-DCM PDs under sunlight and UV light $\left(\lambda_{\mathrm{EX}}=365 \mathrm{~nm}\right)$, respectively.

Consequently, the proposed reaction mechanism is summarized in Figure 6D. It is clear that there are two fluorescent centers and a crosslink-enhanced emission in 2.0G PAMAMDCM PDs. One is the $\mathrm{C}=\mathrm{O}$ bonds, which emit a light-yellow fluorescence. Another is the $\pi$-conjugated off-domain systems obtained by the reaction among DCM, C=O, and internal amine groups of PAMAM, generating a blue light. The other is the crosslinkenhanced emission combined with the reaction of DCM and internal multiple amines, and the aggregation of carbonyl groups, enhancing the fluorescence. Combinations of multiple factors make the 2.0G PAMAM-DCM PDs exhibit a stronger blue fluorescence.

As a result, DCM is the key role in the fluorescence emission of 2.0G PAMAM-DCM PDs. The internal factors that dominated the emission may result from DCM: (1) the reaction of DCM and internal amine groups $\left(-\mathrm{NH},-\mathrm{NR}_{2}\right)$ of PAMAM, but not the external primary amine $\left(-\mathrm{NH}_{2}\right)$, which is controlled by the nucleophilic property of DCM; (2) DCM induces the crosslinking due to the shortened distances of branched chains of PAMAM; (3) DCM restricts the transfer, rotation, and vibration of lone-pair electrons on the amine group, causing the aggregation of carbonyl groups.

\subsection{Metal Ion Sensing Performance}

Owing to a good water solubility and fluorescent property of 2.0G PAMAM-DCM PDs, the chemical-sensing performance of the 2.0G PAMAM-DCM PDs was tested with different metal cations, including alkali metal ions $\left(\mathrm{Na}^{+}\right.$and $\left.\mathrm{K}^{+}\right)$, alkaline earth metal ions $\left(\mathrm{Ca}^{2+}\right.$ and $\mathrm{Mg}^{2+}$ ), and transition metal ions (bivalence: $\mathrm{Cu}^{2+}, \mathrm{Cd}^{2+}, \mathrm{Zn}^{2+}, \mathrm{Hg}^{2+}$; trivalence: $\mathrm{Fe}^{3+}$ and $\mathrm{Al}^{3+}$ ). Figure $7 \mathrm{~A}, \mathrm{~B}$ show that the fluorescence intensities of $\mathrm{Hg}^{2+}, \mathrm{K}^{+}, \mathrm{Mg}^{2+}$, and $\mathrm{Cu}^{2+}$ slightly decreased, and $\mathrm{Fe}^{3+}$ greatly quenched the fluorescence, suggesting that $\mathrm{Fe}^{3+}$ ions have a selective quenching effect on 2.0G PAMAM-DCM PDs. The photographs captured under UV light illustrated a strong blue color that was quenched to weak blue, which was generally in agreement with the phenomenon of $\mathrm{NaBH} 4$ reduction. This indicates that carbonyl groups could intimately bind with $\mathrm{Fe}^{3+}$ ions, and destroy the aggregation and the $\mathrm{n} \rightarrow \pi^{*}$ electronic transition of the $\mathrm{C}=\mathrm{O}$ bond (yellow fluorescence center). Thus, 2.0G PAMAM-DCM PDs can specifically recognize $\mathrm{Fe}^{3+}$ ions and form stable complexes.

In addition, the high selectivity of the fluorescence probe depends on the precise limit of detection. The detection limits of 2.0G PAMAM-DCM PDs to $\mathrm{Fe}^{3+}$ ions in water were recorded in Figure 7C. The intensity of blue light keeps decreasing until completely quenching, along with the increasing concentration of $\mathrm{Fe}^{3+}$ ions in the range of $10 \mu \mathrm{M}$ to $300 \mu \mathrm{M}$. A linear tendency between the $\mathrm{Fe}^{3+}$ concentration and fluorescence intensity of 2.0G PAMAM-DCM PDs presented. A linear equation describing the relationship between fluorescence intensity and $\mathrm{Fe}^{3+}$ concentration was obtained by fitting the data. $\mathrm{Y}=-0.69434 \mathrm{X}+0.01478, \mathrm{R}_{1}^{2}=0.9968$, where $\mathrm{Y}$ is fluorescence intensity of 2.0G PAMAMDCM PDs, $\mathrm{X}(\mu \mathrm{M})$ is $\mathrm{Fe}^{3+}$ concentration. Based on this tendency, a corresponding linear Stern-Volmer equation $\left(F-F_{0}\right) / F=0.00199 X+0.02339, R_{2}^{2}=0.9976$ can be designed to obtain the detection limit. Where $\mathrm{X}(\mu \mathrm{M})$ is $\mathrm{Fe}^{3+}$ concentration, $\mathrm{F}$ and $\mathrm{F}_{0}$ represent the fluorescence intensity of 2.0G PAMAM-DCM PDs in the absence and presence of $\mathrm{Fe}^{3+}$, respectively. The Stern-Volmer constant (s) is 0.00199. As a result, the detection limit is $56.6 \mathrm{nM}$ (nM level), which represents the promotion of two orders of magnitude of the minimum value of $\mathrm{Fe}^{3+}(5.37 \mu \mathrm{M})$ in drinking water released by the US Environmental Protection Agency. Consequently, the 2.0G PAMAM-DCM PDs probes can extend biological applications and environmental monitoring. 

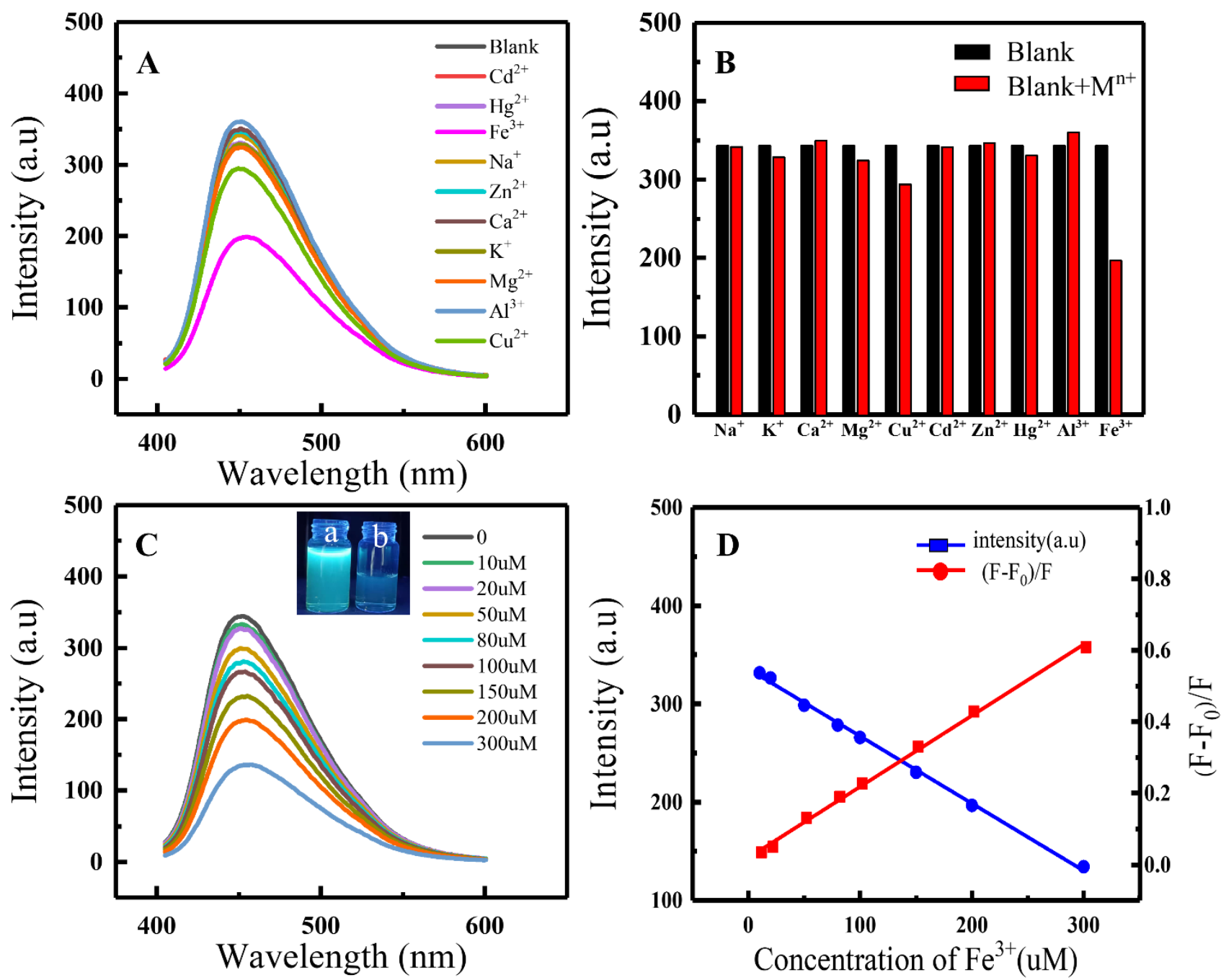

Figure 7. (A) Fluorescence intensity curves of metal ions detection (the concentration of the 2.0G PAMAM-DCM PDs is $0.1 \mathrm{mg} / \mathrm{mL}$ and all metal ions are $200 \mu \mathrm{M})$. (B) The metal ions' selectivity results. (C) Fluorescence-intensity curves of $\mathrm{Fe}^{3+}$ detection. (D) The linear relationship between fluorescence intensity and $\mathrm{Fe}^{3+}$ concentration. Insets in (C) are photographs of (a) 2.0G PAMAM-DCM PDs and (b) 2.0G PAMAM-DCM PDs with $200 \mu \mathrm{M} \mathrm{Fe}^{3+}$.

\section{Conclusions}

In this work, 2.0G PAMAM was employed as a carbon source to improve the compatibility and modification of PDs, and DCM was used to enhance the fluorescence properties, to obtain blue 2.0G PAM-DCM PDs by a one-step hydrothermal method. The quantum yield of 2.0G PAMAM-DCM PDs was 32.1\%, which is greatly enhanced-25 times that of the 2.0G PAMAM-also exhibiting remarkable $\mathrm{pH}$ - and temperature-responsive fluorescence properties. DCM played a key role in limiting the unshared electron transition of the internal amine functional groups as well as their rotations and vibrations. It formed the strongest and most stable fluorescence intensity under neutral conditions at $100{ }^{\circ} \mathrm{C}$. At the same time, the PDs can be transformed into carbon dots higher than $100{ }^{\circ} \mathrm{C}$, indicating that the carbonization degree would be accelerated from 2.0G PAMAM-DCM molecules on the shell. In addition, 2.0G PAMAM-DCM PDs show remarkable $\mathrm{Fe}^{3+}$ sensing properties in aqueous media, with great selectivity and the LOD of $56.6 \mathrm{nM}$, which is much lower than the international minimum standard ( $\mu \mathrm{M}$ level). The design strategy of 2.0G PAMAM-DCM is significant for controlling structural modification, improving fluorescence properties of PDs, and extending applications for biological tracing and environmental assessment. 


\begin{abstract}
Author Contributions: Conceptualization, X.W., W.S., B.D. and J.S.; methodology, X.W., Y.W., D.C., J.L., S.X., W.L., W.S., B.D. and J.S; experiment and characterization, X.W., Y.W., D.C., J.L., S.X. and W.L.; resources, B.D., W.S. and J.S.; writing-original draft preparation, X.W., Y.W. and W.L.; writingreview and editing, X.W., Y.W., D.C., J.L., S.X., W.L., W.S., B.D. and J.S. All authors have read and agreed to the published version of the manuscript.
\end{abstract}

Funding: This work was supported by the National Natural Science Foundation of China (Nos. 82073475), Major Basic Research Projects of Shandong Natural Science Foundation (ZR2020ZD36), the Graduate Student Innovation Research Project of Northeast Petroleum University (JYCX_CX03_2018), and the Project of Jilin Provincial Department of Health (ZYXWST2021061).

Institutional Review Board Statement: Not applicable.

Informed Consent Statement: Not applicable.

Data Availability Statement: Data can be made available upon request from the corresponding author.

Acknowledgments: We are grateful to the research group of Xiaoyang Liu (State Key Laboratory of Inorganic Synthesis and Preparative Chemistry, College of Chemistry, Jilin University), microscopic test center of the Northeast Petroleum University for characterization, and the Daqing Ecological Environment Monitoring Center for environmental assessment.

Conflicts of Interest: The authors declare no conflict of interest.

\title{
References
}

1. Diaz, C.; Benitez, C.; Vidal, F.; Barraza, L.F.; Jiménez, V.A.; Guzman, L.; Fuentealba, J.; Yevenes, G.E.; Alderete, J.B. Cytotoxicity and in vivo plasma kinetic behavior of surface-functionalized PAMAM dendrimers. Nanomed. Nanotechnol. Biol. Med. 2018, 14, 2227-2234. [CrossRef] [PubMed]

2. Cong, H.; Zhou, L.; Meng, Q.; Zhang, Y.; Yu, B.; Shen, Y.; Hu, H. Preparation and evaluation of PAMAM dendrimer-based polymer gels physically cross-linked by hydrogen bonding. Biomater. Sci. 2019, 7, 3918-3925. [CrossRef] [PubMed]

3. Gholipour-Mahmoudalilou, M.; Roghani-Mamaqani, H.; Azimi, R.; Abdollahi, A. Preparation of hyperbranched poly (amidoamine)-grafted graphene nanolayers as a composite and curing agent for epoxy resin. Appl. Surf. Sci. 2018, 428, 1061-1069. [CrossRef]

4. Martins, I.; Tomás, H.; Lahoz, F.; Rodrigues, J. Engineered fluorescent carbon dots and G4-G6 PAMAM dendrimer nanohybrids for bioimaging and gene delivery. Biomacromolecules 2021, 22, 2436-2450. [CrossRef] [PubMed]

5. Yang, L.; Wang, H.; Li, D.; Li, L.; Lou, X.; Liu, H. Self-nucleation and self-assembly of highly fluorescent Au5 nanoclusters for bioimaging. Chem. Mater. 2018, 30, 5507-5515. [CrossRef]

6. Kamil, Y.M.; Al-Rekabi, S.H.; Yaacob, M.H.; Syahir, A.; Chee, H.Y.; Mahdi, M.A.; Bakar, M.H.A. Detection of dengue using PAMAM dendrimer integrated tapered optical fiber sensor. Sci. Rep. 2019, 9, 13483. [CrossRef]

7. Yang, D.; Zhang, R.; Zhao, T.; Sun, T.; Chu, X.; Liu, S.; Tang, E.; Xu, X. Efficient reduction of 4-nitrophenol catalyzed by 4-carbo-methoxypyrrolidone modified PAMAM dendrimer-silver nanocomposites. Catal. Sci. Technol. 2019, 9, 6145-6151. [CrossRef]

8. Guerra, J.; Cantillo, D.; Kappe, C.O. Visible-light photoredox catalysis using a macromolecular ruthenium complex: Reactivity and recovery by size-exclusion nanofiltration in continuous flow. Catal. Sci. Technol. 2016, 6, 4695-4699. [CrossRef]

9. Fana, M.; Gallien, J.; Srinageshwar, B.; Dunbar, G.L.; Rossignol, J. PAMAM dendrimer nanomolecules utilized as drug delivery systems for potential treatment of glioblastoma: A systematic review. Int. J. Nanomed. 2020, 15, 2789. [CrossRef]

10. Vu, M.T.; Bach, L.G.; Nguyen, D.C.; Ho, M.N.; Nguyen, N.H.; Tran, N.Q.; Nguyen, D.H.; Nguyen, C.K.; Hoang Thi, T.T. Modified carboxyl-terminated PAMAM dendrimers as great cytocompatible nano-based drug delivery system. Int. J. Mol. Sci. 2019, 20, 2016. [CrossRef]

11. Wang, D.; Imae, T. Fluorescence emission from dendrimers and its pH dependence. J. Am. Chem. Soc. 2004, 126, 13204-13205. [CrossRef]

12. Shi, W.; Lu, X.; Zhang, S.; Li, H.; Liu, M.; Dong, B. C=N based PAMAM polymer dots: Fluorescent property and Cu ${ }^{2+}$ sensing application. Colloid. Surface A 2020, 585, 124112. [CrossRef]

13. Campos, B.B.; Oliva, M.M.; Contreras-Cáceres, R.; Rodriguez-Castellón, E.; Jiménez-Jiménez, J.; da Silva, J.C.E.; Algarra, M. Carbon dots on based folic acid coated with PAMAM dendrimer as platform for Pt (IV) detection. J. Colloid. Interface Sci. 2016, 465, 165-173. [CrossRef] [PubMed]

14. Campos, B.B.; Contreras-Cáceres, R.; Bandosz, T.J.; Jiménez-Jiménez, J.; Rodríguez-Castellón, E.; da Silva, J.C.E.; Algarra, M. Carbon dots as fluorescent sensor for detection of explosive nitrocompounds. Carbon 2016, 106, 171-178. [CrossRef]

15. Wang, D.; Imae, T.; Miki, M. Fluorescence emission from PAMAM and PPI dendrimers. J. Colloid. Interface Sci. 2007, 306, $222-227$. [CrossRef] [PubMed] 
16. El-Betany, A.M.; Kamoun, E.A.; James, C.; Jangher, A.; Aljayyoussi, G.; Griffiths, P.; McKeown, N.B.; Gumbleton, M. Autofluorescent PAMAM-based dendritic molecules and their potential application in pharmaceutical sciences. Int. J. Pharmaceut. 2020, 579, 119187. [CrossRef] [PubMed]

17. Lu, H.; Feng, L.; Li, S.; Zhang, J.; Lu, H.; Feng, S. Unexpected strong blue photoluminescence produced from the aggregation of unconventional chromophores in novel siloxane-poly (amidoamine) dendrimers. Macromolecules 2015, 48, 476-482. [CrossRef]

18. Ji, Y.; Qian, Y. A study using quantum chemical theory methods on the intrinsic fluorescence emission and the possible emission mechanisms of PAMAM. RSC Adv. 2014, 4, 58788-58794. [CrossRef]

19. Konopka, M.; Janaszewska, A. Klajnert-Maculewicz, B., Intrinsic fluorescence of PAMAM dendrimers-Quenching studies. Polymers 2018, 10, 540. [CrossRef] [PubMed]

20. Georgiev, N.I.; Asiri, A.M.; Qusti, A.H.; Alamry, K.A.; Bojinov, V.B. Design and synthesis of pH-selective fluorescence sensing PAMAM light-harvesting dendrons based on 1, 8-naphthalimides. Sens. Actuat. B Chem. 2014, 190, 185-198. [CrossRef]

21. Lu, H.; Zhang, J.; Feng, S. Controllable photophysical properties and self-assembly of siloxane-poly (amidoamine) dendrimers Phys. Chem. Chem. Phys. 2015, 17, 26783-26789. [CrossRef] [PubMed]

22. Zhu, S.; Song, Y.; Zhao, X.; Shao, J.; Zhang, J.; Yang, B. The photoluminescence mechanism in carbon dots (graphene quantum dots, carbon nanodots, and polymer dots): Current state and future perspective. Nano Res. 2015, 8, 355-381. [CrossRef]

23. Tao, S.; Zhu, S.; Feng, T.; Xia, C.; Song, Y.; Yang, B. The polymeric characteristics and photoluminescence mechanism in polymer carbon dots: A review. Mater. Today Chem. 2017, 6, 13-25. [CrossRef]

24. Feng, T.; Zhu, S.; Zeng, Q.; Lu, S.; Tao, S.; Liu, J.; Yang, B. Supramolecular cross-link-regulated emission and related applications in polymer carbon dots. ACS Appl. Mater. Inter. 2017, 10, 12262-12277. [CrossRef]

25. Vallan, L.; Urriolabeitia, E.P.; Ruipérez, F.; Matxain, J.M.; Canton-Vitoria, R.; Tagmatarchis, N.; Benito, A.M.; Maser, W.K. Supramolecular-enhanced charge transfer within entangled polyamide chains as the origin of the universal blue fluorescence of polymer carbon dots. J. Am. Chem. Soc. 2018, 140, 12862-12869. [CrossRef]

26. Noun, F.; Jury, E.A.; Naccache, R. Elucidating the quenching mechanism in carbon dot-metal interactions- designing sensitive and selective optical probes. Sensors 2021, 21, 1391. [CrossRef]

27. Zhou, Y.; Sharma, S.K.; Peng, Z.; Leblanc, R.M. Polymers in carbon dots: A review. Polymers 2017, 9, 67. [CrossRef]

28. Sakthivel, P.; Sekar, K.; Sivaraman, G.; Singaravadivel, S. Rhodamine-benzothiazole conjugate as an efficient multimodal sensor for $\mathrm{Hg}^{2+}$ ions and its application to imaging in living cells. New J. Chem. 2018, 42, 11665-11672. [CrossRef]

29. Bendicho, C.; Lavilla, I.; Pena-Pereira, F.; De la Calle, I.; Romero, V. Nanomaterial-integrated cellulose platforms for optical sensing of trace metals and anionic species in the environment. Sensors 2021, 21, 604. [CrossRef]

30. Ansari, S.; Masoum, S. Recent advances and future trends on molecularly imprinted polymer-based fluorescence sensors with luminescent carbon dots. Talanta 2021, 223, 121411. [CrossRef]

31. Shangguan, J.; Huang, J.; He, D.; He, X.; Wang, K.; Ye, R.; Yang, X.; Qing, T.; Tang, J. Highly Fe ${ }^{3+}$-selective fluorescent nanoprobe based on ultrabright N/P codoped carbon dots and its application in biological samples. Anal. Chem. 2017, 89, 7477-7484 [CrossRef] [PubMed]

32. Baluta, S.; Lesiak, A.; Cabaj, J. Simple and cost-effective electrochemical method for norepinephrine determination based on carbon dots and tyrosinase. Sensors 2020, 20, 4567. [CrossRef] [PubMed]

33. Yap, S.H.K.; Chan, K.K.; Tjin, S.C.; Yong, K.-T. Carbon Allotrope-Based Optical Fibers for Environmental and Biological Sensing: A Review. Sensors 2020, 20, 2046. [CrossRef] [PubMed]

34. Xie, Y.; Cheng, D.; Liu, X.; Han, A. Green hydrothermal synthesis of N-doped carbon dots from biomass highland barley for the detection of $\mathrm{Hg}^{2+}$. Sensors 2019, 19, 3169. [CrossRef]

35. Zhu, L.; Xiao, C.; Dai, X.; Li, J.; Gui, D.; Sheng, D.; Chen, L.; Zhou, R.; Chai, Z.; Albrecht-Schmitt, T.E. Exceptional perrhenate/pertechnetate uptake and subsequent immobilization by a low-dimensional cationic coordination polymer: Overcoming the hofmeister bias selectivity. Environ. Sci. Technol. Let. 2017, 4, 316-322. [CrossRef]

36. Coates, J. Interpretation of infrared spectra, a practical approach. In Encyclopedia of Analytical Chemistry; Meyers, R.A., Ed.; John Wiley \& Sons Ltd.: Chichester, UK, 2000; pp. 10815-10837.

37. Liu, B.; Zhang, H.; Liu, S.; Sun, J.; Zhang, X.; Tang, B.Z. Polymerization-induced emission. Mater. Horiz. 2020, 7, 987-998. [CrossRef]

38. Herbani, Y.; Suliyanti, M.M. Concentration effect on optical properties of carbon dots at room temperature. J. Lumin. 2018, 198, 215-219.

39. Adsetts, J.R.; Hoesterey, S.; Gao, C.; Love, D.A.; Ding, Z. Electrochemiluminescence and photoluminescence of carbon quantum dots controlled by aggregation-induced emission, aggregation-caused quenching, and interfacial reactions. Langmuir 2020, 36, 14432-14442. [CrossRef]

40. Zhu, S.; Song, Y.; Shao, J.; Zhao, X.; Yang, B. Non-conjugated polymer dots with crosslink-enhanced emission in the absence of fluorophore units. Angew. Chem. Int. Edit. 2015, 54, 14626-14637. [CrossRef] 